BMJ Paediatrics Open

\section{Hypothermia for encephalopathy in low-income and middle-income countries: feasibility of whole-body cooling using a low-cost servo- controlled device}

To cite: Oliveira V, Kumutha JR, $\mathrm{E} \mathrm{N}$, et al. Hypothermia for encephalopathy in lowincome and middle-income countries: feasibility of whole-body cooling using a low-cost servo-controlled device. BMJ Paediatrics Open 2018;2:e000245. doi:10.1136/ bmjpo-2017-000245

$\mathrm{V} 0$ and $\mathrm{J}$ contributed equally.

Received 18 December 2017 Revised 3 February 2018 Accepted 14 February 2018
Check for updates

For numbered affiliations see end of article.

Correspondence to Dr Sudhin Thayyil; s.thayyil@ imperial.ac.uk

\section{ABSTRACT}

Although therapeutic hypothermia $(\mathrm{TH})$ is the standard of care for hypoxic ischaemic encephalopathy in highincome countries, the safety and efficacy of this therapy in low-income and middle-income countries (LMICs) is unknown. We aimed to describe the feasibility of $\mathrm{TH}$ using a low-cost servo-controlled cooling device and the short-term outcomes of the cooled babies in LMIC.

Design We recruited babies with moderate or severe hypoxic ischaemic encephalopathy (aged $<6$ hours) admitted to public sector tertiary neonatal units in India over a 28-month period. We administered whole-body cooling (set core temperature $33.5^{\circ} \mathrm{C}$ ) using a servocontrolled device for 72 hours, followed by passive rewarming. We collected the data on short-term neonatal outcomes prior to hospital discharge.

Results Eighty-two babies were included-61 (74\%) had moderate and 21 (26\%) had severe encephalopathy Mean (SD) hypothermia cooling induction time was 1.7 hour (1.5) and the effective cooling time $95 \%(0.08)$. The mean (SD) hypothermia induction time was 1.7 hour (1.5 hour), core temperature during cooling was $33.4^{\circ} \mathrm{C}$ $(0.2)$, rewarming rate was $0.34^{\circ} \mathrm{C}\left(0.16^{\circ} \mathrm{C}\right)$ per hour and the effective cooling time was $95 \%(8 \%)$. Twenty-five $(51 \%)$ babies had gastric bleeds, $6(12 \%)$ had pulmonary bleeds and $21(27 \%)$ had meconium on delivery. Fifteen (18\%) babies died before discharge from hospital. Heart rate more than $120 \mathrm{bpm}$ during cooling $(\mathrm{P}=0.01)$ and gastric bleeds $(P<0.001)$ were associated with neonatal mortality.

Conclusions The low-cost servo-controlled cooling device maintained the core temperature well within the target range. Adequately powered clinical trials are required to establish the safety and efficacy of $\mathrm{TH}$ in LMICs.

Clinical trial registration number NCT01760629.

\section{What is already known on this topic?}

Therapeutic hypothermia (TH) improves neurodevelopmental outcomes after moderate or severe neonatal encephalopathy in high-income countries.

- Core temperature needs to be maintained within a narrow target range for optimal neuroprotection.

\section{What this study hopes to add?}

Effective TH can be provided using a low-cost servo-controlled cooling device in low-income and middle-income countries.

- Bleeding problems, particularly gastric bleeds, frequently occur in babies with encephalopathy undergoing cooling therapy in these settings and are associated with high mortality.

Hypoxic ischaemic encephalopathy (HIE) accounts for 1 million infant deaths every year, and more than half of the surviving infants develop lifelong neurodisability. ${ }^{1}$ Therapeutic hypothermia $(\mathrm{TH})$ reduces mortality and improves survival with normal neurological outcome after HIE in high-income countries $^{2-5}$ and is now offered as standard care in these settings. ${ }^{6}$

There are several challenges in extrapolating the safety and efficacy data of cooling therapy from high-income countries to low-income and middle-income countries (LMICs), which shoulder $99 \%$ of the disease burden. 
First, the population comorbidities are very different, and there is far higher incidence of foetal growth restriction, meconium aspiration and perinatal sepsis in LMICs; these may reduce the neuroprotective effect of cooling. Second, in high-income countries, cooling is provided only in specialist cooling centres with facilities for optimal intensive care support and with high nursing to patient ratios. Such facilities and staffing resourcing levels are not available in most LMIC neonatal units. Finally, for effective neuroprotection, it is essential to rapidly reduce the core body temperature and precisely maintain this within the target range $\left(33^{\circ} \mathrm{C}\right.$ to $\left.34^{\circ} \mathrm{C}\right)$ for 72 hours. Deviations from these regimes with overcooling or undercooling, or prolonging the duration of therapy, may be potentially harmful. ${ }^{7}$ Thus, in high-income countries, TH is administered using sophisticated and expensive servo-controlled devices, ${ }^{8}$ which are unaffordable in LMICs.

Despite the lack of evidence, TH is an increasingly used routine clinical practice in LMIC. A recent survey of cooling practices in India ${ }^{9}$ suggested that most units offering cooling therapy use various improvised local solutions including air conditioning, ice packs and phasechanging materials to manually achieve cooling, but the efficacy of these methods is still debatable, and they may be associated with increased monitoring and staffing requirements. ${ }^{8}$ Here, we report the feasibility and effectiveness of using an affordable servo-controlled system for whole-body cooling in public sector neonatal units in India and the short-term outcomes of the cooled babies.

\section{METHODS}

We recruited term babies (aged $<6$ hours; birth weight $\geq 1.8 \mathrm{~kg}$ ) requiring resuscitation at birth and with moderate or severe HIE, from five large public sector hospitals in India (Madras Medical College, Chennai; Indira Gandhi Institute of Child Health, Bangalore; Lokmanya Tilak Municipal General Hospital, Mumbai; Jawaharlal Nehru Institute of Postgraduate Medical Education and Research, Puducherry and Government Medical College, Calicut), between April 2013 and August 2015. These hospitals are funded by the Indian government and offer free healthcare to low-income populations. All centres are regional neonatal intensive care units with facilities for cardiorespiratory support and neonatal surgery. However, invasive blood pressure monitoring, inhaled nitric oxide and amplitude-integrated electroencephalography (aEEG) are not available. We trained the medical staff at the recruiting centres in the Eunice Kennedy Shriver National Institute of Child Health and Human Development (NICHD) neurological staging of neonatal encephalopathy (table 1) prior to the start of the study. ${ }^{2}$

We excluded babies who were born in moribund condition, as well as those who had any major life-threatening congenital malformations, or if the cooling device was not available (ie, already in use) at the time of recruitment. The University College London ethics committee and the ethics committee of each participating hospital approved the study. We obtained informed parental consent prior to recruitment.

\section{Procedures}

We initiated cooling by keeping the baby naked with a nappy on the cooling mattress, inserting a core temperature monitoring probe, turning off radiant warmers and switching on the machine (Tecotherm HELIX, Inspiration Healthcare) (figure 1). The device had a single set temperature of $33.5^{\circ} \mathrm{C}$. Following a rapid induction phase, the device maintained core body temperature between $33^{\circ} \mathrm{C}$ and $34^{\circ} \mathrm{C}$ for 72 hours, servo-controlled to rectal or oesophageal temperature. After 72 hours of cooling, we removed the mattress and rewarmed the baby passively using three layers of clothing, without using a radiant warmer. Once the baby's temperature reached $36.5^{\circ} \mathrm{C}$, we restarted the overhead radiant warmer (servo-controlled to avoid hyperthermia). We documented the vital parameters every 15 min during the first hour and then hourly until 90 hours after the start of cooling.

Clinical management protocols were unaltered by study participation. We monitored the haemogram, biochemistry, blood cultures (where available) and liver function throughout the first 4 days. We obtained antenatal and delivery data on all babies. We also collected data on medications (antibiotics, anticonvulsants, inotropes and sedatives), ventilation and the use of blood products up to hospital discharge.

\section{Sample size and statistical analysis}

We expected the cooling device to have comparable efficacy to the standard servo-controlled cooling device used in high-income countries-that is, over $90 \%$ effective cooling time (percentage of time during which the rectal temperature is effectively within the target temperature $\left(33^{\circ} \mathrm{C}\right.$ to $\left.34^{\circ} \mathrm{C}\right)$ during the entire cooling period).$^{8}$ Assuming an effective cooling time of $90 \%$, to estimate this percentage with an uncertainty of $\pm 7 \%$ (with a $95 \%$ confidence level), 74 babies needed to be recruited. We increased the sample size to 82 to allow for a $10 \%$ rate of early mortality (prior to the completion of cooling).

The associations between clinical variables and mortality were examined. The unpaired t-test or MannWhitney test was used to compare the continuous variables between survivors and non-survivors, whereas Fisher's exact test was used to compare categorical variables between groups. We used IBM SPSS (V.24; IBM, New York, USA) and STATA (V.15; StataCorp, Texas, USA) for all data analysis.

\section{RESULTS}

Out of 173 babies screened, 91 did not meet the eligibility criteria (age $>6$ hours; mild encephalopathy; non-availability of the device). We enrolled the remaining 82 into this study after informed parental consent (49 babies from Institute of Child Health, Madras Medical College, 
Table 1 Classification of neonatal encephalopathy (NICHD neurological examination)

\begin{tabular}{|c|c|c|c|c|}
\hline \multirow[b]{2}{*}{ Categories (total 6) } & \multicolumn{4}{|c|}{ Signs of NE in each category (circle the most appropriate level) } \\
\hline & Normal & Mild NE & Moderate NE & Severe NE \\
\hline \multicolumn{5}{|c|}{ 1. Level of consciousness } \\
\hline & $\begin{array}{l}\text { Alert, responsive to } \\
\text { external stimuli (state } \\
\text { dependent, } \\
\text { eg, postfeeds) }\end{array}$ & $\begin{array}{l}\text { Hyperalert, has a stare, } \\
\text { jitteriness, high-pitched } \\
\text { cry, exaggerated } \\
\text { responds to minimal } \\
\text { stimuli, inconsolable }\end{array}$ & Lethargic & Stupor/coma \\
\hline
\end{tabular}

2. Spontaneous activity

Changes position Normal or decreased Decreased activity No activity

when awake

3. Posture

$\begin{array}{llll}\text { Predominantly flexed } & \begin{array}{l}\text { Mild flexion of distal } \\ \text { joints (fingers, wrist } \\ \text { when quiet }\end{array} & \begin{array}{l}\text { Moderate flexion of } \\ \text { distal joint, complete } \\ \text { extension }\end{array} & \text { Decerebrate }\end{array}$

4. Tone

$\begin{array}{llll}\begin{array}{l}\text { Strong flexor tone in } \\ \text { all extremities+strong } \\ \text { flexor hip tone }\end{array} & \begin{array}{l}\text { Normal or slightly } \\ \text { increased peripheral } \\ \text { tone }\end{array} & \begin{array}{l}\text { Hypotonia (focal or } \\ \text { general) or hypertonia }\end{array} & \begin{array}{l}\text { Flaccid } \\ \text { rigid }\end{array} \\ & & & \end{array}$

5. Primitive reflexes (circle only the highest level in each sign; the maximum score is only one in any one category)
$\begin{array}{cllll}\text { Suck } & \text { Strong, easily illicit } & \text { Weak, poor } & \text { Weak but has a bite Absent } \\ \text { Moro } & \text { Complete } & \begin{array}{l}\text { Partial response, low } \\ \text { threshold to illicit }\end{array} & \text { Incomplete } & \text { Absent }\end{array}$

6. Autonomic system (circle only the highest level in each sign; the maximum score is only one in any one category)

\begin{tabular}{|c|c|c|c|c|}
\hline Pupils & $\begin{array}{l}\text { In dark: } 2.5-4.5 \mathrm{~mm} \\
\text { In light: } 1.5-2.5 \mathrm{~mm}\end{array}$ & Mydriasis & Constricted & $\begin{array}{l}\text { Deviation/dilated/non- } \\
\text { reactive to light }\end{array}$ \\
\hline Heart rate & 100-160 bpm & Tachycardia (HR >160) & Bradycardia $(H R<100)$ & Variable HR \\
\hline Respiration & Regular respirations & $\begin{array}{l}\text { Hyperventilation (RR } \\
>60 / \text { min) }\end{array}$ & Periodic breathing & $\begin{array}{l}\text { Apnoea or requires } \\
\text { ventilator }\end{array}$ \\
\hline \multicolumn{5}{|l|}{ Total score } \\
\hline *Seizure & None & None & Yes/no & Yes/no \\
\hline
\end{tabular}

Infant who has seizure will be moderate or severe NE depending on the neurological exam. Seizure with normal or mild NE or moderate NE on neurological exam will be 'moderate NE'. Seizure with severe NE will be 'severe NE'. The level of encephalopathy will be assigned based on which level of signs (moderate or severe) predominates among the six categories. If moderate and severe signs are equally distributed, the designation is then based on the highest level in category no 1: the level of consciousness.

HR, heart rate; NE, neonatal encephalopathy; NICHD, National Institute of Child Health and Human Development; RR, regular respiration.

Chennai; 14 babies from Indira Gandhi Institute of Child Health, Bangalore; 10 babies from Lokmanya Tilak Municipal General Hospital, Mumbai; 9 babies from Jawaharlal Nehru Institute of Postgraduate Medical Education and Research, Puducherry). Sixty-one (74\%) babies had moderate and 21 (26\%) had severe encephalopathy. Fifteen (18\%) babies died before discharge from hospital $(5(8 \%)$ babies with moderate encephalopathy and $10(47 \%)$ with severe encephalopathy).

Overall, $19(24 \%)$ babies were inborn at the recruiting centre, $57(73 \%)$ were born at another hospital and 2 $(3 \%)$ were born at home. The majority of babies $(66 \%-$ $85 \%$ ) were born via spontaneous vaginal delivery, 8 $(9.8 \%)$ via emergency caesarean section, $2(3 \%)$ via non-emergency caesarean section and $2(3 \%)$ via instrumental vaginal delivery. The mean $(\mathrm{SD})$ maternal age was 22.8 (2.9) years, and mean gestational age was 38.7 (1.3) weeks. Mean birth weight was 2901 (365) g and head circumference $33.7(0.7) \mathrm{cm}$. Mean (SD) Apgar scores were $4.5(1.3)$ at $5 \mathrm{~min}$ and 6.3 (1) at $20 \mathrm{~min}$. Sixty-four babies were men $(65 \%)$.

Clinical seizures were present within the first 6 hours in $68(87 \%)$ babies. Pregnancy complications were reported in $5(7 \%)$ cases and delivery complications in $9(12 \%)$. Meconium stained liquor was reported in $19(27 \%)$ babies and maternal fever during labour occurred in 3 $(4 \%)$ cases. The baseline characteristics of survivors and non-survivors are given in table 2.

\section{Therapeutic effectiveness of the cooling device}

Mean (SD) age at the start of cooling was 3.7 (1.4) hours. Target cooling temperature was achieved within 1 hour of start of cooling in $37(45 \%)$ of the babies and within 2 hours for $63(77 \%)$ of the babies. Three babies $(4 \%)$ 


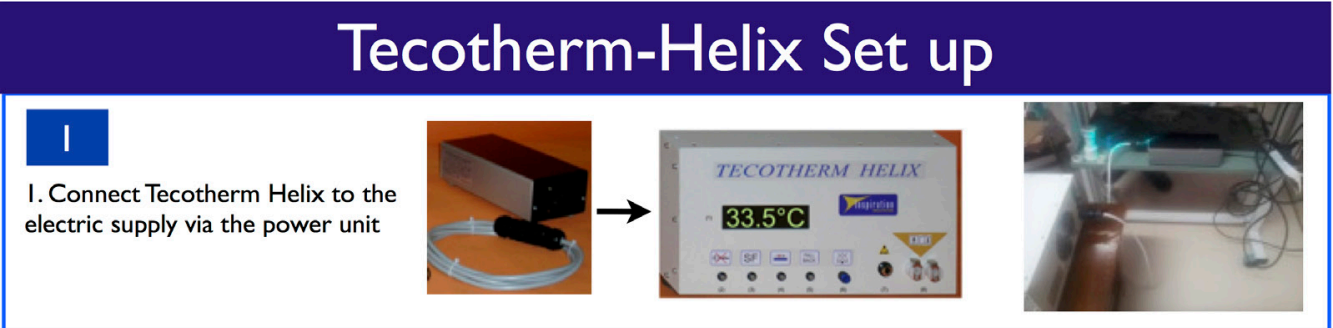

\section{2}

2. Connect Tecotherm Helix to the mattress using the hose
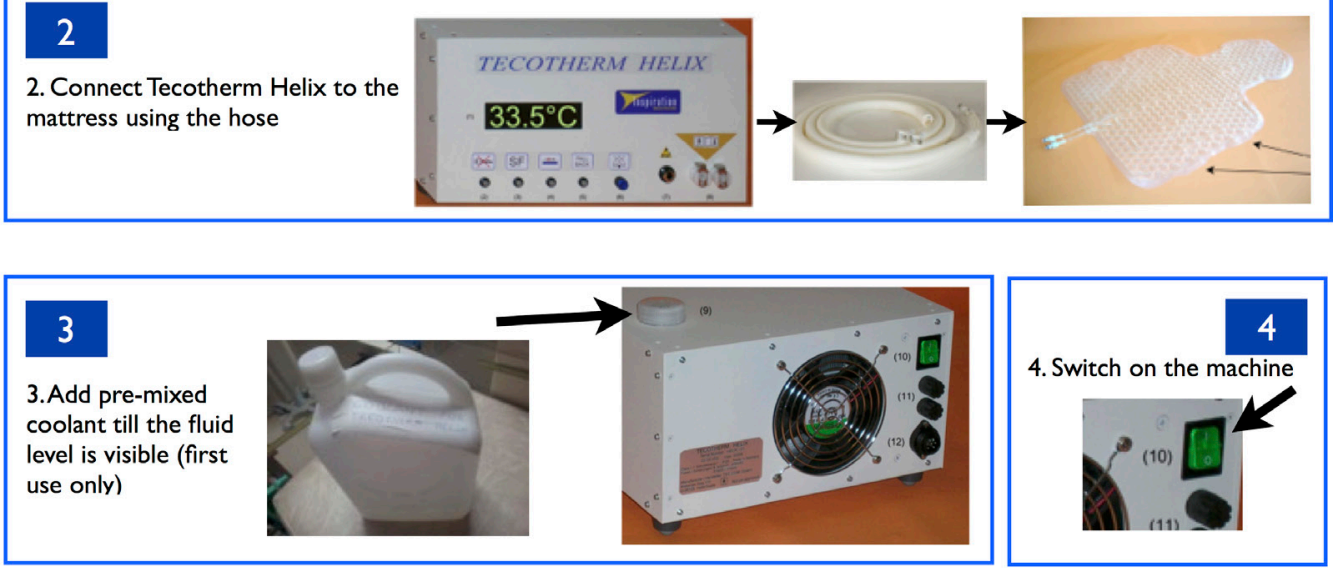

\section{5}

5.Add more pre-mixed coolant holding the mattress vertical so that the air bubbles escape and mattress is fully filled with fluid
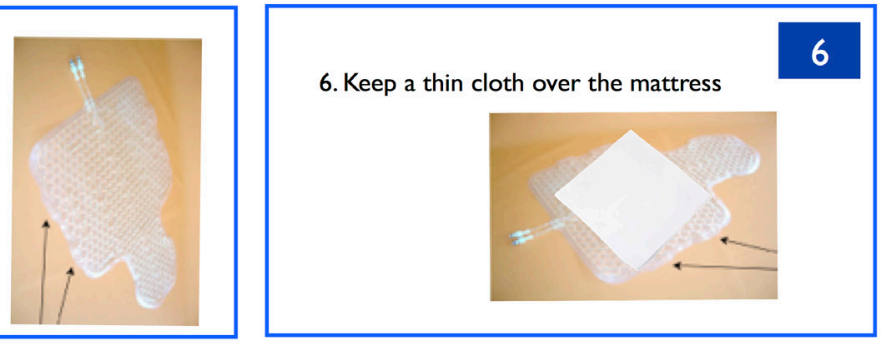

\section{7}

Keep baby on the mattress,

Attach the rectal probe to tecotherm helix (red arrow) Insert the rectal probe (4 to $6 \mathrm{~cm}$ ) (blue arrow)

Wrap the mattress around the baby using a small tape (non-sticking) through the mattress eye hole (black arrow) (green arrow)

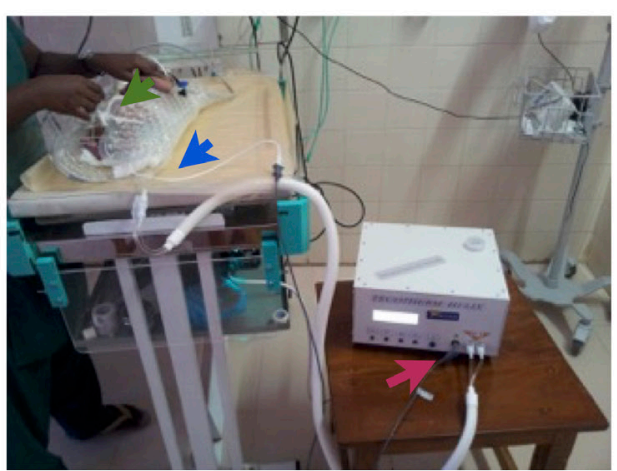

Figure 1 Setting up of Tecotherm HELIX cooling device.

took more than 3 hours to reach target cooling temperature. The mean (SD) baseline temperature before start of cooling was $35.5^{\circ} \mathrm{C}(1.5)$, and babies took on average 1.7 hour (1.5) to reach target temperature range (defined as time at which core temperature dropped below $34^{\circ} \mathrm{C}$ ).

During cooling treatment, mean (SD) temperature was $33.4^{\circ} \mathrm{C}(0.24)$, and cooling phase lasted on average 72.2 hours (2.1). Time within target core temperature (effective cooling time) of $33^{\circ} \mathrm{C}$ to $34^{\circ} \mathrm{C}$ was $95 \%$ (0.08). Passive rewarming phase lasted on average 11.3 hours
(5.8) with an average rewarming rate of $0.34^{\circ} \mathrm{C}(0.16)$ per hour. Of 71 babies, $35(50 \%)$ took more than 10 hours to reach normothermia. Rectal temperature probes were used in 75 babies $(91 \%)$, and oesophageal probes were used in 7 babies (9\%). The effectiveness during cooling and rewarming is presented in figure 2 .

\section{Clinical status and ongoing care}

The majority of babies were on intravenous (only) fluids for the first 4 days (varying from $76(93 \%)$ on day 1 to 
Table 2 Baseline characteristics of survivors and non-survivors

\begin{tabular}{|c|c|c|c|}
\hline & $\begin{array}{l}\text { Survivors } \\
(n=67)\end{array}$ & Non-survivors $(n=15)$ & $P$ values \\
\hline Maternal age (years) & $22.6 \pm 3.0$ & $24.0 \pm 1.8$ & 0.37 \\
\hline Gestational age (weeks) & $38.8 \pm 1.3$ & $38.0 \pm 1.2$ & 0.14 \\
\hline Age at start of cooling (hours) & $3.6 \pm 1.4$ & $4.1 \pm 1.4$ & 0.22 \\
\hline Birth weight $(g)$ & $2912 \pm 364$ & $2855 \pm 388$ & 0.58 \\
\hline Head circumference $(\mathrm{cm})$ & $33.7 \pm 0.8$ & $33.9 \pm 0.4$ & 0.49 \\
\hline 1 min Apgar-median (IQR) & $1(0)$ & $2(2)$ & 0.33 \\
\hline 5 min Apgar - median (IQR) & $4(0)$ & $4.5(2)$ & 0.60 \\
\hline 10 min Apgar - median (IQR) & $5.0(0)$ & $5.0(0)$ & 0.36 \\
\hline 20 min Apgar - median (IQR) & $7.0(0)$ & NA & - \\
\hline Gender (male) & $45 / 66(68 \%)$ & $8 / 15(53 \%)$ & 0.37 \\
\hline Severe encephalopathy & $11 / 67(16 \%)$ & $10 / 15(67 \%)$ & $<0.001$ \\
\hline Seizures within 6 hours of birth & $55 / 64(86 \%)$ & $13 / 14(93 \%)$ & 0.68 \\
\hline Complications in pregnancy & $4 / 64(6 \%)$ & $1 / 12(8 \%)$ & 1.00 \\
\hline Complications during delivery & 9/64 (14\%) & 0/13 (0\%) & 0.34 \\
\hline Meconium stained liquor & $13 / 60(22 \%)$ & $6 / 11(55 \%)$ & 0.06 \\
\hline Maternal fever during labour & $2 / 64(3 \%)$ & $1 / 13(8 \%)$ & 0.43 \\
\hline \multicolumn{4}{|l|}{ Place of delivery } \\
\hline Inborn & $15 / 65(23 \%)$ & 4/13 (31\%) & \\
\hline Outborn - hospital & $48 / 65(74 \%)$ & $9 / 13(69 \%)$ & 0.81 \\
\hline Outborn- home & $2 / 65(3 \%)$ & 0/13 (0\%) & \\
\hline \multicolumn{4}{|l|}{ Delivery method } \\
\hline Prelabour LSCS & 2/65 (3\%) & 0/13 (0\%) & \\
\hline Emergency LSCS & $6 / 65(9 \%)$ & $2 / 13(15 \%)$ & 0.82 \\
\hline Spontaneous vaginal delivery & $55 / 65(85 \%)$ & $13 / 13(85 \%)$ & \\
\hline Instrumental vaginal delivery & $2 / 65(3 \%)$ & $0 / 13(0 \%)$ & \\
\hline \multicolumn{4}{|l|}{ Neonatal complications } \\
\hline Gastric bleeds & $14 / 38(37 \%)$ & $11 / 11(100 \%)$ & $<0.001$ \\
\hline Pulmonary haemorrhage & $1 / 38(3 \%)$ & $5 / 11(45 \%)$ & 0.001 \\
\hline PPHN & $1 / 38(3 \%)$ & $6 / 11(55 \%)$ & $<0.001$ \\
\hline Thrombocytopenia & $42 / 67(63 \%)$ & $10 / 15$ (67\%) & 1.00 \\
\hline Metabolic acidosis & $26 / 67(39 \%)$ & $9 / 15(60 \%)$ & 0.16 \\
\hline \multicolumn{4}{|l|}{ Treatment duration (days) } \\
\hline Invasive ventilation & $1.4 \pm 1.8$ & $3.3 \pm 1.5$ & 0.002 \\
\hline Sedation & $0.9 \pm 1.5$ & $1.4 \pm 1.8$ & 0.40 \\
\hline Inotropic support & $3.1 \pm 1.3$ & $3.9 \pm 0.3$ & 0.04 \\
\hline Anticonvulsive drugs & $2.9 \pm 1.7$ & $3.9 \pm 0.3$ & 0.07 \\
\hline
\end{tabular}

LSCS, lower segment caesarean section; PPHN, persistent pulmonary hypertension.

Mean values \pm SD or proportion (percentage), unless specified otherwise.

$54(66 \%)$ on day 4$)$. Three babies $(4 \%)$ received enteral feeds via nasogastric tube on day 1 and, by day 4 , there were $2(2 \%)$ babies on full nasogastric feeds and 17 (21\%) receiving a combination of intravenous plus nasogastric intake.

Thirty-seven babies $(46 \%)$ required invasive ventilation during the first 24 hours. Most babies required treatment with anticonvulsive drugs (59 $(77 \%)$ on day 1 to $52(72 \%)$ on day 4$)$, using mainly phenobarbitone $(53 \%$ on day 1 to $64 \%$ of the babies on day 4) or multiple drugs (13\% to $18 \%$ of the babies). Sixty-three $(82 \%)$ babies required some inotropic support on day 1 , decreasing to 48 babies $(68 \%)$ on day 4. Main inotropes used were a combination of dopamine and dobutamine. Requirement of 
38

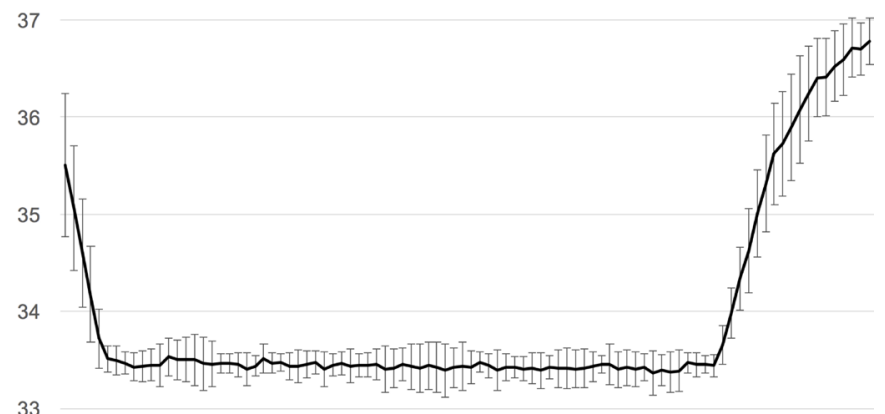

33

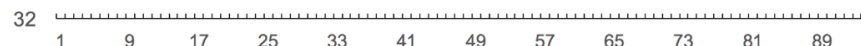

Figure 2 Mean (SD-error bars) temperature during cooling and rewarming.

inotropic support during the first 4 days was higher for non-survivors (mean 3.9 days vs 3.0 days, $\mathrm{P}=0.000,95 \%$ CI $(-1.64$ to -0.3$))$, but only $25 \%(12 / 48)$ of babies requiring inotropic support on day 4 died. Sedation was used in $22(37 \%)$ babies. This corresponded to $14(19 \%)$, $18(25 \%), 17$ (24\% and $18(26 \%)$ between days 1 and 4 , respectively). When using sedation, choral hydrate and fentanyl were the preferred sedatives $(53 \%$ and $41 \%$, respectively).

The mean (SD) heart rate of the babies who died was $121 \mathrm{bpm}$ (17 bpm), which was higher than those who survived, who had a mean $(\mathrm{SD})$ heart rate of $111 \mathrm{bpm}$ (13 bpm) ( $\mathrm{P}=0.008)$ (figure 2$)$. The babies who died were more likely to have a heart rate higher than $120 \mathrm{bpm}$ (93\% vs $51 \% ; \mathrm{P}=0.005)$ and more persistently elevated heart rate $(>120 \mathrm{bpm})$ (median of 5 hours compared with a median of 1 hour) than those who survived $(\mathrm{P}=0.01)$. Duration of heart rate above $120 \mathrm{bpm}$ did not appear to be associated with sedation or sedation days, neither did

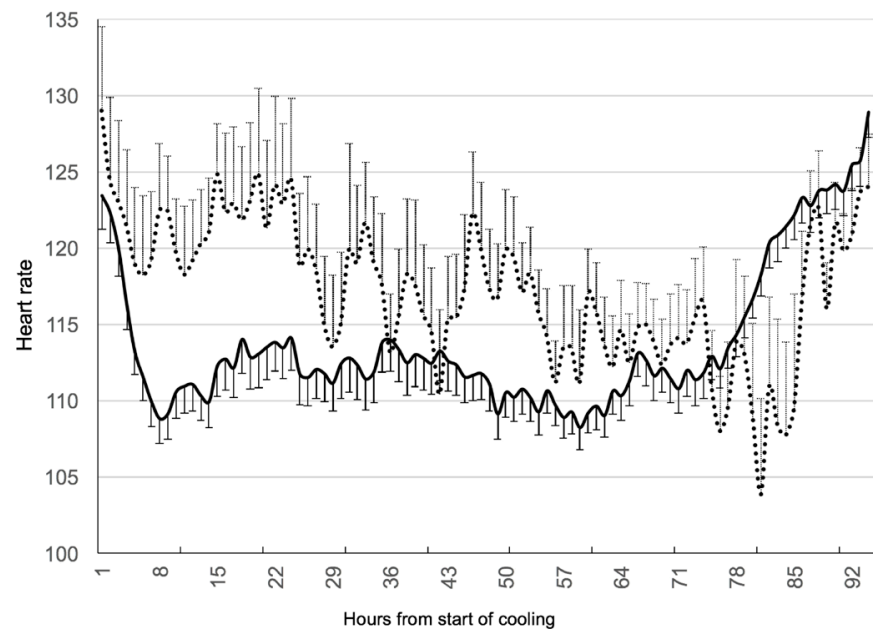

Figure 3 Mean (SD-error bars) heart rate (bpm) during cooling and rewarming. The dotted line represents nonsurvivors, and the continuous line represents survivors. sedation (lack of) seem to be associated with mortality. Figure 3 presents the average heart rate during treatment.

Only one baby had hypoglycaemia (blood sugar level below $45 \mathrm{mg} / \mathrm{dL}(2.5 \mathrm{mmol} / \mathrm{L}))$, which occurred on day 1. Metabolic acidosis (absolute base excess <-10) persisted for more than 24 hours in 4 (13\%) babies. Fifty-two babies $(64 \%)$ had thrombocytopenia (platelet count below $\left.100 \times 10^{9} / \mathrm{L}\right)$. C reactive protein was available only for 20 babies, and the mean (SD) on days 1 to 4 were 4.8 (3.0), 8.4 (12.8), 22.9 (22.1) and 48.6 (62.7), respectively. There was no growth in any of the 49 blood cultures (automated) obtained at the time of recruiting.

Gastric bleed (defined as fresh blood $>5 \mathrm{~mL}$ from nasogastric tube) was recorded in 25/49 (51\%) and pulmonary haemorrhage (defined as copious bloody secretions with clinical deterioration requiring change(s) in ventilatory management) in 6/49 $(12 \%)$ of the babies (table 3 ). There was no significant difference between those with and without gastric bleeds for any of birth weight, sedation or severity of encephalopathy. However, there was a highly significant association between gastric bleeds and mortality. No patients without gastric bleeds died, whereas almost half (44\%) of patients with a gastric bleed died. The bleeds were treated with blood product transfusions (fresh frozen plasma, packed cell transfusions and platelets).

Persistent pulmonary hypertension (defined as severe hypoxaemia disproportionate to the severity of lung disease with a significant pre-postductal saturation difference on pulse oximetry) occurred in $7 / 49$ (14\%) of the babies. Persistent pulmonary hypertension was managed by vasopressors and by optimising conventional ventilation. Inhaled nitric oxide was not available.

\section{DISCUSSION}

The data presented here have several important messages for the clinicians in LMICs and will inform the design of future cooling trials in these settings. First, TH can be effectively delivered using a low-cost servo-controlled whole-body cooling device without the need for additional nursing resources. Whereas concerns about the loss of therapeutic effectiveness and increased workload associated with high oscillations during manual cooling have been described previously, ${ }^{8}$ the effective cooling times achieved in our study were reassuring that a low-cost servo-controlled cooling device may offer a promising alternative. In addition, a high thermal efficacy and stability of the device used in this study suggests that this method may not only hold better therapeutic effect but also sustain or even reduce staff demand. As the study used a pragmatic approach, the treatment requirements and decisions were continued from what had been locally practised until the study. Although we have not formally collected feedback from staff on the challenges of delivering TH, we observed a fast-paced learning curve which was facilitated by the ease of operation of a simplified 
Table 3 Comparison of babies with encephalopathy with and without gastric bleeds

\begin{tabular}{|c|c|c|c|c|c|c|}
\hline \multirow[b]{2}{*}{ Variable } & \multicolumn{2}{|c|}{ No gastric bleed } & \multicolumn{2}{|c|}{ Gastric bleed } & \multirow[b]{2}{*}{$P$ values } & \multirow{2}{*}{$\begin{array}{l}\text { Mean/proportion } \\
\text { difference }(95 \% \text { Cls) }\end{array}$} \\
\hline & $\mathbf{n}$ & Summary & $n$ & Summary & & \\
\hline Mean (SD) birth weight (g) & 24 & $2925 \pm 249$ & 25 & $2967 \pm 386$ & 0.66 & 42 (228 to -146$)$ \\
\hline Sedation during cooling & 19 & $4(21 \%)$ & 18 & $5(28 \%)$ & 0.71 & $7 \%(-20 \%$ to $33 \%)$ \\
\hline Mortality & 24 & $0(0 \%)$ & 25 & $11(44 \%)$ & $<0.001$ & $44 \%(22 \%$ to $63 \%)$ \\
\hline
\end{tabular}

equipment, suggesting there was no increase in the required intensity of care.

Our servo-controlled device is based on Tecotherm-Neo, a widely used whole-body cooling device in high-income countries. Although the device has similar safety features, cost reduction was achieved by simplifying the design with a single set target temperature of $33.5^{\circ} \mathrm{C}$. The coolant was tap water, mixed with locally available surgical spirit (90\% alcohol). The device lacked a rewarming mode, hence the rewarming was passive by removing the baby from the cooling mattress. This increased the rewarming duration and the variability of core temperature during rewarming. The device has been modified to include a constant rewarming since then and is currently being CE (Conformité Européene) marked. It is likely that the eventual costs (approximately US\$1000) of this device would be one-tenth of high-income country cooling devices.

Second, the short clinical term morbidity of babies with encephalopathy in this setting was different to high-income countries. There was a very high incidence of gastric bleeds $(25 / 49,51 \%)$, although we did not have data on gastric bleeds for all the participants and we had data for more non-survivors than survivors. The reason for gastric bleeds is unclear, and none of the babies had evidence of perforation or necrotising enterocolitis. It is possible that the bleeds were multiple in utero ischaemic events; however, no relation with birth weight and gastric bleed was seen on regression model. There was no relation of sedation and gastric bleeds indicating that stress of cooling was an unlikely contributor to these bleeds.

Coagulopathy is a well-known complication of hypoxic ischaemic encephalopathy, and gastrointestinal bleeding has been reported in up to $25 \%$ of the babies undergoing $\mathrm{TH}$ in high-income countries. ${ }^{10} 11$ Cooling studies from LMICs have not yet reported such bleeds as yet. In these settings, it is possible that gastric bleeds were not specifically looked for or recorded in the case record forms and hence were overlooked. The incidence of pulmonary bleed was also much higher than the published data from high-income countries. ${ }^{12}$

We also observed a persistently higher heart rate above 120 bpm during cooling in non-survivors, which was independent of sedative use. Association of tachycardia during cooling and increased mortality in neonatal encephalopathy has been reported previously. ${ }^{13}$ It is possible that this elevated heart rate is a reflection of the underlying disease severity and cardiac dysfunction.
There are several limitations of this feasibility study. We were unable to perform autopsy in any of the babies due to a lack of parental consent and, hence, were unable to find the cause of the gastric bleeds. As there was no control arm, it is unclear if the gastric bleeds were related to the underlying condition or to the cooling therapy. Although blood cultures were obtained, we have not performed detailed screening for infection using polymerise chain reaction methods, and hence we might have missed coexistent sepsis. Finally, we have not performed any neuroimaging or assessed the neurodevelopmental outcomes.

A number of small randomised controlled trials of cooling therapy have been reported from LMIC. The pooled data from these studies do not suggest an improvement in neonatal mortality. ${ }^{14}$ Only one of these studies had reported neurodevelopment outcomes at 18 months or more, and the authors claimed that cooling significantly reduced death and neurodisability. ${ }^{15}$ An indigenous (China) servo-controlled head cooling device was used in this study. This study was of poor quality, and relevance of the findings remains unclear. Since then, one more pilot randomised control involving 60 encephalopathy babies (30 each allocated to cooling and usual care) from India has been reported. Authors claimed adverse outcomes (death or neurodisability at 30 months) in 6/30 (20\%) of cooled babies and 18/30 (60\%) of usual care babies $(\mathrm{P}=0.0015)$. Adverse outcomes related to cooling were minimal. Selective head cooling was attempted using ice in this study, which had been previously shown to be unreliable in administrating effective TH. ${ }^{16}$ Hence, it is unclear if any survival benefits in this study were related to the intervention.

Most studies in LMICs have used water bottles, ice or frozen gels pack to induce $\mathrm{TH} .^{17-22}$ While such manual methods are suitable and safe when there is close nursing monitoring to ensure that core temperature is maintained in the target range, ${ }^{23}$ most LMIC neonatal units do not have adequate nursing resources. We have previously reported the use of phase change material for $\mathrm{TH}$ in India. ${ }^{24}$ Given that the phase change materials are inexpensive (US\$20) and widely available, cooling devices can be easily developed from these. However, in our experience, the cooling efficacy of phase change materials was weak and required low ambient temperatures to induce cooling, which limits the wider use. ${ }^{24}$ Nevertheless, cooling devices using phase change material is now commercially marketed in India, and several centres are using these devices. ${ }^{25}$ 
Considering the differences in comorbidities, maternal ill health and healthcare resources in LMICs, adequately powered and designed clinical trials are required to answer the question of whether TH is safe and beneficial for babies with moderate or severe encephalopathy in these settings. ${ }^{7}$ Despite the lack of evidence, many centres in India and other LMICs are now routinely offering cooling therapy to babies with neonatal encephalopathy using a wide range of indigenous cooling devices. ${ }^{9}$

The data presented in this feasibility study will inform the study design of future cooling trials in LMIC. Our inclusion criteria were purely clinical so as to increase the generalisability of the therapy in LMIC, where blood gas and aEEG are not routinely available. A large pragmatic trial of hypothermia for neonatal encephalopathy is currently underway in India, Bangladesh and Sri Lanka. ${ }^{26}$ A total of 408 babies with moderate and severe encephalopathy will be randomised to whole-body cooling using a servo-controlled cooling device or usual care. All babies have detailed infection screen and 3 Tesla MRI and spectroscopy in addition to detailed neurodevelopmental assessment at 18 months. The study protocol of the HELIX trial is available online and may be useful for clinicians in LMIC who wish to offer TH in these settings.

\author{
Author affiliations \\ ${ }^{1}$ Centre for Perinatal Neuroscience, Imperial College London, London, UK \\ ${ }^{2}$ Neonatal Medicine, Institute of Child Health, Madras Medical College, Chennai, \\ Tamil Nadu, India \\ ${ }^{3}$ Neonatal Medicine, Indira Gandhi Institute of Child Health, Bangalore, Karnataka, \\ India \\ ${ }^{4}$ Neonatal Medicine, Cloudnine Hospital, Chennai, Tamil Nadu, India \\ ${ }^{5}$ Neonatal Medicine, Imperial College Healthcare NHS Trust, London, UK \\ ${ }^{6}$ Neonatal Medicine, Perinatal Trials Unit, Bangalore, India \\ ${ }^{7}$ Neonatal Medicine, Lokmanya Tilak Municipal Hospital, Sion, Mumbai, India \\ ${ }^{8}$ Neonatal Medicine, Jawaharlal Institute of Postgraduate Medical Education \& \\ Research, Pondicherry, India \\ ${ }^{9}$ Neonatal Medicine, Calicut Medical College, Kozhikode, Kerala, India \\ ${ }^{10}$ Medical Statistics, Stats Consultancy, London, UK \\ ${ }^{11}$ Neonatal Medicine, Maulana Azad Medical College, New Delhi, Delhi, India \\ ${ }^{12}$ Neonatal Medicine, Wayne State University, Detroit, Michigan, USA
}

Collaborators Wayne State University, USA: SS; Imperial College London, UK: GA, MC, Jethro Herberg, PJL, JMe, PM, VO, RS, ST; Stats Consultancy, Amersham, UK: PBas; Bangabandhu Sheikh Mujib Medical University, Dhaka, Bangladesh: Arjun Chandra Dey, Sanjoy Kumer Dey, Mohammed Tariqul Islam, Ismat Jahan, Mohammed Abdul Mannan, Sadeka Chowdhury Moni, Kamrul Hasan Shabuj, Mohammod Shahidullah; National Institute of Neurosciences \& Hospital, Dhaka, Bangladesh: Mohammed Nazrul Islam, Mst. Nazmun Nahar; Maulana Azad Medical College, New Delhi, India: Ashish Jain, SR; Lokmanya Tilak Municipal Medical College, Sion, Mumbai, India: SM, JMo, KD, Swapnil Bhiskar; Institute of Child Health, Egmore, Madras Medical College, Chennai, India: Rema Chandramohan, KC, JK, MS, NE, Monica Sebastian, Padmesh Vadekepad; Indira Gandhi Institute of Child Health, Bangalore, India: NB, PB, Usha Kantharajanna, Sowmya Krishnappa, JS, Niranjan Hunsanhalli Shivanna; Institute of Obstetrics \& Gynaecology, Madras Medical College, Chennai, India: Arasar Seeralar, Vinayagam Prakash, Mythilli Babu, Mohamed Sajjid; Barnard Institute of Radiology, Madras Medical College, Chennai, India: Babu Peter Sathyanathan, R Ravi; Jawaharlal Nehru Institute of Postgraduate Medical Education and Research, Pondicherry, India: SB, VB; Institute of Maternal and Child Health, Government Medical College, Calicut, India: VM, MN; University of Kelaniya, Sri Lanka: Kalpani Chathurangika, Sanjeewa Munasinghe, Radika Karunaratne Shaman Rajindrajith, Ranmali Rodrigo, Samanmali Sumanasena, Jithangi Wanigasinghe; Sree Avittom Thirunal Hospital, Thiruvananthapuram, India Radhika Ajit, Sobha Kumar, Ashwathy Nair.
Contributors V0 analysed and interpreted the data and wrote the initial drafts of the manuscript. KK, NE, MS and KC assisted in the study design and supervised the recruitment and data collection in Chennai. JS, NB and PBan led the recruitment at Bangalore. MC and RS assisted in the data collection and interpretation of data. $\mathrm{JMo}, \mathrm{KD}$ and $\mathrm{SM}$ assisted in the study design and supervised the recruitment and data collection in Mumbai. SB and VM assisted in the study design and supervised the recruitment and data collection in Pondicherry. VM and MN assisted in the study design and supervised the recruitment and data collection in Calicut. PJL, PM, GA and JMe assisted in the data interpretation and preparation of the manuscript. PM undertook the statistical analysis. SR, SS and ST (chief investigator) conceived the idea, designed the study and interpreted the data. All authors contributed to the development of the manuscript and approved the final version for publication.

Funding This study was funded by the Gates and Melinda Foundation and Weston Garfield Foundation. The study was coordinated by the Centre for Perinatal Neuroscience at Imperial College London, which receives funding from the NIHR Imperial Biomedical Research Centre.

Competing interests None declared.

Patient consent Obtained from the parents/guardian.

Ethics approval University College London Research Ethics Committee.

Provenance and peer review Not commissioned; externally peer reviewed.

Open Access This is an Open Access article distributed in accordance with the Creative Commons Attribution Non Commercial (CC BY-NC 4.0) license, which permits others to distribute, remix, adapt, build upon this work non-commercially, and license their derivative works on different terms, provided the original work is properly cited and the use is non-commercial. See: http://creativecommons.org/ licenses/by-nc/4.0/

(C) Article author(s) (or their employer(s) unless otherwise stated in the text of the article) 2018. All rights reserved. No commercial use is permitted unless otherwise expressly granted.

\section{REFERENCES}

1. Lawn JE, Cousens S, Zupan J. Lancet Neonatal Survival Steering Team. 4 million neonatal deaths: when? Where? Why? Lancet 2005;365:891-900.

2. Shankaran S, Laptook AR, Ehrenkranz RA, et al. Whole-body hypothermia for neonates with hypoxic-ischemic encephalopathy. $N$ Engl J Med 2005;353:1574-84.

3. Shankaran S, Pappas A, McDonald SA, et al. Childhood outcomes after hypothermia for neonatal encephalopathy. $N$ Engl J Med 2012;366:2085-92.

4. Azzopardi D, Strohm B, Marlow N, et al. Effects of hypothermia for perinatal asphyxia on childhood outcomes. $N$ Engl J Med 2014;371:140-9.

5. Azzopardi DV, Strohm B, Edwards AD, et al. Moderate hypothermia to treat perinatal asphyxial encephalopathy. $N$ Engl J Med 2009;361:1349-58.

6. National Institute for Health and Clinical Excellence. Therapeutic hypothermia with intracorporeal temperature monitoring for hypoxic

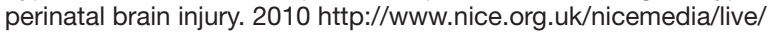
11315/48809/.pdf

7. Montaldo P, Pauliah SS, Lally PJ, et al. Cooling in a low-resource environment: lost in translation. Semin Fetal Neonatal Med 2015;20.

8. Robertson NJ, Kendall GS, Thayyil S. Techniques for therapeutic hypothermia during transport and in hospital for perinatal asphyxial encephalopathy. Semin Fetal Neonatal Med 2010;15:276-86.

9. Chandrasekaran M, Swamy R, Ramji S, et al. Therapeutic Hypothermia for Neonatal Encephalopathy in Indian Neonatal Units: A Survey of National Practices. Indian Pediatr 2017;54:969-70.

10. Pakvasa MA, Winkler AM, Hamrick SE, et al. Observational study of haemostatic dysfunction and bleeding in neonates with hypoxicischaemic encephalopathy. BMJ Open 2017;7:e013787.

11. Forman KR, Diab Y, Wong EC, et al. Coagulopathy in newborns with hypoxic ischemic encephalopathy $(\mathrm{HIE})$ treated with therapeutic hypothermia: a retrospective case-control study. BMC Pediatr 2014;14:277.

12. Jacobs SE, Berg M, Hunt R, et al. Cooling for newborns with hypoxic ischaemic encephalopathy. Cochrane Database Syst Rev 2013:CD003311.

13. Elstad M, Liu X, Thoresen M. Heart rate response to therapeutic hypothermia in infants with hypoxic-ischaemic encephalopathy. Resuscitation 2016;106:53-7. 
14. Pauliah SS, Shankaran S, Wade A, et al. Therapeutic hypothermia for neonatal encephalopathy in low- and middle-income countries: a systematic review and meta-analysis. PLoS One 2013;8:e58834.

15. Zhou WH, Cheng GQ, Shao XM, et al. Selective head cooling with mild systemic hypothermia after neonatal hypoxic-ischemic encephalopathy: a multicenter randomized controlled trial in China. $J$ Pediatr 2010;157:367-72.

16. Horn AR, Woods DL, Thompson C, et al. Selective cerebral hypothermia for post-hypoxic neuroprotection in neonates using a solid ice cap. S Afr Med J 2006;96(Pt 2):976-81.

17. Thomas N, George KC, Sridhar S, et al. Whole body cooling in newborn infants with perinatal asphyxial encephalopathy in a low resource setting: a feasibility trial. Indian Pediatr 2011;48:445-51.

18. Bharadwaj SK, Bhat BV. Therapeutic hypothermia using gel packs for term neonates with hypoxic ischaemic encephalopathy in resource-limited settings: a randomized controlled trial. $J$ Trop Pediatr 2012;58:382-8.

19. Gane BD, Nandhakumar S, Bhat V, et al. Effect of therapeutic hypothermia on chromosomal aberration in perinatal asphyxia. $J$ Pediatr Neurosci 2016;11:25-8.

20. Gane BD, Bhat V, Rao R, et al. Effect of therapeutic hypothermia on DNA damage and neurodevelopmental outcome among term neonates with perinatal asphyxia: a randomized controlled trial. $J$ Trop Pediatr 2014:60:134-40.

21. Joy R, Pournami F, Bethou A, et al. Effect of therapeutic hypothermia on oxidative stress and outcome in term neonates with perinatal asphyxia: a randomized controlled trial. $J$ Trop Pediatr 2013;59:17-22.

22. Robertson NJ, Nakakeeto M, Hagmann C, et al. Therapeutic hypothermia for birth asphyxia in low-resource settings: a pilot randomised controlled trial. Lancet 2008;372:801-3.

23. Jacobs SE, Morley CJ, Inder TE, et al. Whole-body hypothermia for term and near-term newborns with hypoxic-ischemic encephalopathy: a randomized controlled trial. Arch Pediatr Adolesc Med 2011:165:692-700.

24. Thayyil S, Shankaran S, Wade A, et al. Whole-body cooling in neonatal encephalopathy using phase changing material. Arch Dis Child Fetal Neonatal Ed 2013;98:F280-F281.

25. Thomas $\mathrm{N}$, Abiramalatha $\mathrm{T}$, Bhat $\mathrm{V}$, et al. Phase changing material for therapeutic hypothermia in neonates with hypoxic ischemic encephalopathy - a multi-centric study. Indian Pediatr 2017.

26. Thayyil S, Oliveira V, Lally PJ, et al. Hypothermia for encephalopathy in low and middle-income countries (HELIX): study protocol for a randomised controlled trial. Trials 2017;18:432. 